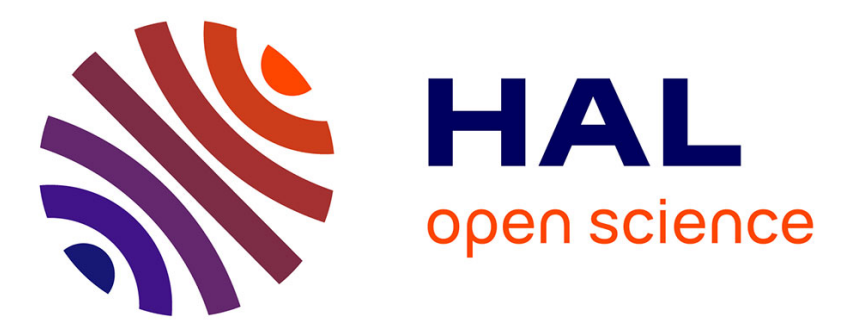

\title{
Resolving ZnO-based coaxial core-multishell heterostructure by electrical scanning probe microscopy
} Lin Wang, Corinne Sartel, Said Hassani, Vincent Sallet, Georges Bremond

\section{To cite this version:}

Lin Wang, Corinne Sartel, Said Hassani, Vincent Sallet, Georges Bremond. Resolving ZnO-based coaxial core-multishell heterostructure by electrical scanning probe microscopy. Applied Physics Letters, 2018, 113 (22), pp.222103. 10.1063/1.5054685 . hal-02072861

\section{HAL Id: hal-02072861 \\ https://hal.science/hal-02072861}

Submitted on 10 Dec 2021

HAL is a multi-disciplinary open access archive for the deposit and dissemination of scientific research documents, whether they are published or not. The documents may come from teaching and research institutions in France or abroad, or from public or private research centers.
L'archive ouverte pluridisciplinaire HAL, est destinée au dépôt et à la diffusion de documents scientifiques de niveau recherche, publiés ou non, émanant des établissements d'enseignement et de recherche français ou étrangers, des laboratoires publics ou privés. 
Resolving ZnO-based coaxial core-multishell heterostructure by electrical scanning probe microscopy

Lin Wang, Corinne Sartel, Said Hassani, Vincent Sallet, and Georges Brémond

Citation: Appl. Phys. Lett. 113, 222103 (2018); doi: 10.1063/1.5054685

View online: https://doi.org/10.1063/1.5054685

View Table of Contents: http://aip.scitation.org/toc/apl/113/22

Published by the American Institute of Physics

THE WORLD'S RESOURCE FOR SOLID STATE CHARACTERIZATION
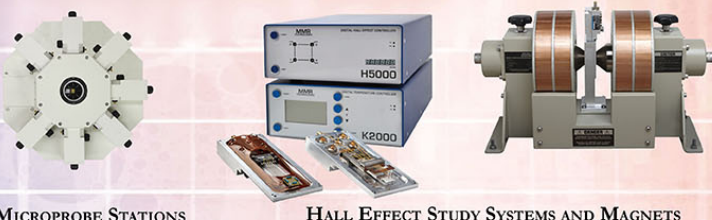

Hall EfFect Study Systems and Magnets 


\title{
Resolving ZnO-based coaxial core-multishell heterostructure by electrical scanning probe microscopy
}

\author{
Lin Wang, ${ }^{1, a), b)}$ Corinne Sartel, ${ }^{2}$ Said Hassani, ${ }^{2}$ Vincent Sallet, ${ }^{2}$ and Georges Brémond ${ }^{1}$ \\ ${ }^{1}$ Institut des Nanotechnologies de Lyon (INL), Université de Lyon, CNRS UMR 5270, INSA Lyon, Bat. Blaise \\ Pascal, 7 Avenue Jean Capelle, 69621 Villeurbanne, France \\ ${ }^{2}$ Groupe d'étude de la matière condensée (GEMaC), CNRS-Université de Versailles St Quentin en Yvelines, \\ Université Paris-Saclay, 45 Avenue des Etats-Unis, 78035 Versailles, France
}

(Received 2 September 2018; accepted 15 November 2018; published online 30 November 2018)

\begin{abstract}
Coaxially periodic $\mathrm{ZnO} / \mathrm{ZnMgO}$ core-multishell nanowire (NW) heterostructures were grown via a metal organic chemical vapor deposition method. We investigated their electrical properties via the application of two locally resolved electrical scanning probe microscopy techniques, i.e., scanning capacitance microscopy (SCM) and scanning spreading resistance microscopy (SSRM), following a planarization process. As a result, $\mathrm{ZnO}$ and $\mathrm{ZnMgO}$ layers can be unambiguously distinguished by both techniques on NWs with diameters $<1 \mu \mathrm{m}$ and the smallest layer thickness of $10 \mathrm{~nm}$, where a higher free carrier concentration along with a low resistivity is revealed for the $\mathrm{ZnO}$ regions in comparison to $\mathrm{ZnMgO}$ portions, as expected. This work demonstrates the high capability of SCM/ SSRM as supplementary and effective tools for probing local electrical properties within functional complex quasi-1D heterostructures. Published by AIP Publishing.

https://doi.org/10.1063/1.5054685
\end{abstract}

One-dimensional (1D) semiconductor nanowire (NW) heterostructures have been considered as ideal functional components for future-generation electronics and optoelectronics. ${ }^{1-3}$ Two types of NW quantum structures are possible, depending on the composition or structure modulation along either the axial or the radical direction of the NW. For the latter, coaxial NW heterostructures are constructed by growing subsequent uniform and homogeneous layers over the side walls of previous ones, giving rise to quantum confinement effects that make light-emission enhancement and its wavelength tunability possible. ${ }^{4,5}$ To achieve the practical application of these structures, it is of great importance to understand their electrical properties in at least two dimensions. Although the electrical properties of bulk materials and thin films can readily be evaluated by traditional techniques such as four-probe measurement, Hall measurement, and capacitance-voltage $(\mathrm{C}-\mathrm{V})$ measurement, the characterization of NWs has been hampered by their small feature sizes incorporated with complex three-dimensional (3D) nanostructures and thus has been regularly relying on the evaluation of the final device, exampled by field effect transistors (FETs) made from individual NWs. This strategy not only involves a complicated lithography patterning process but also struggles to satisfy the requirement of two dimensional (2D) characterization with high spatial resolution, for instance, in core-shell or core-multishell structured NWs. ${ }^{6,7}$ Until now, efforts have been dedicated to the development of techniques that have access to local electronic characteristics of modern nanoelectronic integrated circuits (ICs) and unprecedented sophisticated nanostructures. ${ }^{8-11}$ Particularly, in the past few decades, scanning capacitance microscopy

\footnotetext{
${ }^{\text {a)} E-m a i l: ~ e l e w l i n @ n u s . e d u . s g . ~}$

b) Present address: Department of Electrical and Computer Engineering, National University of Singapore, Block E4A \#05-06 Engineering Drive 3, Singapore 117576.
}

(SCM) and scanning spreading resistance microscopy (SSRM) have proved powerful for 2D electrical imaging in semiconductors with a nanometer-scale spatial resolution. ${ }^{12-14}$ Previously, we have demonstrated their exploitation in characterizing the local electrical properties of $\mathrm{ZnO}$ and $\mathrm{ZnO}$-based NW structures. ${ }^{15-17}$ To go further, in this work, we investigate the first application of the two techniques to electronically resolving $\mathrm{ZnO} / \mathrm{ZnMgO}$ stacking in core-multishell heterostructures, which have attracted extensive research interest for their potential applications in electronic and optoelectronic fields. ${ }^{2,18-20}$ It turns out that both techniques can clearly differ the two types of layers inside six-layered coaxial NWs with diameters $<1 \mu \mathrm{m}$, demonstrating their potential as supplementary and effective tools for accessing the relevant properties of sophisticated quasi-1D heterostructures.

SEM images of the studied NW samples are shown in Figs. 1(a) and 1(b). The core/multishell structures were grown on a c-plane $\mathrm{ZnO}$ substrate by MOCVD and consist (a)

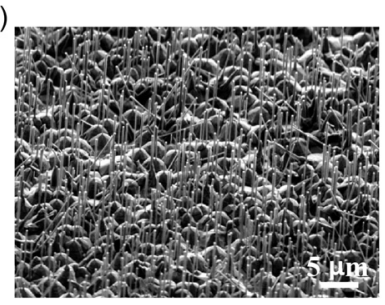

(c)

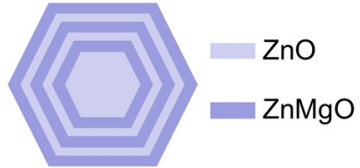

(b)

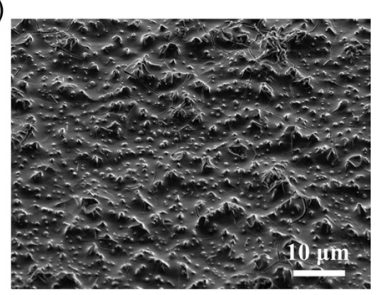

(d)

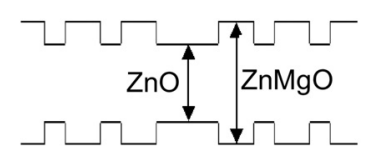

FIG. 1. (a) and (b) SEM images of the metal organic chemical vapor deposition (MOCVD)-grown $\mathrm{ZnO} / \mathrm{ZnMgO}$ multishell NWs before (a) and after (b) the planarization process. (c) Illustration of the ZnO-based co-axial coremultishell NW structure. (d) Band diagram of the multilayer structure. 
of 5 layers epitaxially grown on the core $\mathrm{ZnO} \mathrm{NWs}$, forming a 3-period $\mathrm{ZnO} / \mathrm{ZnMgO}$ coaxial structure, as illustrated in Fig. 1(c). For the initial core $\mathrm{ZnO}$ NWs, diethylzinc (DEZn) and nitrous oxide $\left(\mathrm{N}_{2} \mathrm{O}\right)$ were used as $\mathrm{Zn}$ and oxygen precursors, respectively, and the reactor pressure was maintained at 50 Torr. The NWs spontaneously grew at $850^{\circ} \mathrm{C}$ without any catalyst assistance which have heights of $\sim 9 \mu \mathrm{m}$ and typical diameters less than $200 \mathrm{~nm}^{21}$ Subsequently, $\mathrm{ZnO}$ and $\mathrm{Zn}_{1-\mathrm{x}} \mathrm{Mg}_{\mathrm{x}} \mathrm{O}(\mathrm{x}=0.13)$ surrounding shells were synthesized still using DEZn but a different oxygen source of $\mathrm{O}_{2}$, a lower reaction temperature of $450-500^{\circ} \mathrm{C}$, and a total reactor pressure of 30 Torr. Bismethylcyclopentadienyl-magnesium $(\mathrm{MCp})_{2} \mathrm{Mg}$ was chosen as the $\mathrm{Mg}$ precursor. These conditions allow a quasi-conformal coating over the entire NW. For the entire process, helium was used as carrier gas. It is known that $\mathrm{ZnMgO}$ has a wider bandgap in comparison to $\mathrm{ZnO}$, both materials being n-type. For a $\mathrm{ZnO} / \mathrm{ZnMgO}$ heterostructure, due to the band offsets, $\mathrm{ZnMgO}$ layers may act as barriers, while $\mathrm{ZnO}$ layers create quantum wells [Fig. 1(d)]. A transfer of electrons from $\mathrm{ZnMgO}$ to $\mathrm{ZnO}$ is expected to occur near the interface of the two materials, resulting in an accumulation in $\mathrm{ZnO}$ and the consequent depletion in $\mathrm{ZnMgO}$.

The as-grown vertical NWs are not suitable for the SCM/SSRM scan, which usually requires a flat and smooth surface of the sample. Therefore, a planarization process was conducted. First, the sample was dip-coated with a standard silica sol-gel to embed and consolidate the NWs. Then, chemical-mechanical polishing (CMP) was performed by using a colloidal suspension containing $50 \mathrm{~nm}$-diameter silica nanoparticles to expose the NWs for the SCM/SSRM scan from the top. The unwanted silica nanoparticles remaining on the sample surface were removed using a cotton swab under running deionized water in combination with an ultrasonic process. Backside contacts were realized by large area silver paint on the $\mathrm{ZnO}$ substrate. All the measurements were carried out in the ambient atmosphere using a scanning probe microscope (Digital Instruments Dimension 3100) with SCM/SSRM modules. Pt/Ir coated and conductive diamond (boron doped) coated Si tips were used for SCM and SSRM, respectively.

In SCM, a metal-insulator-semiconductor (MIS) structure is formed between the metal-coated tip and the sample. Its capacitance variation $(\mathrm{dC} / \mathrm{dV})$ is induced by applying an alternating voltage $\left(V_{\mathrm{ac}}\right)$ at tens of kilohertz frequency and can be detected using an ultra-high frequency $(\sim 1 \mathrm{GHz})$ capacitance sensor combined with a lock-in amplifier. ${ }^{12}$ In principle, the amplitude of the $\mathrm{dC} / \mathrm{dV}$ signal is directly related to the carrier concentration in that a material with a lower carrier density depletes more easily and gives rise to a larger $\mathrm{dC} / \mathrm{dV}$ amplitude. Simultaneously, the phase of $\mathrm{dC} / \mathrm{dV}$ contains carrier type information since electrons and holes respond in opposite ways to the modulating voltage. ${ }^{22}$

Typical SCM results are presented in Fig. 2. The topographical AFM image of the $3 \mu \mathrm{m} \times 1 \mu \mathrm{m}$ scanned area is given in Fig. 2(a). The NWs and their multi-shell structure show distinguishable topology contrast, which is likely a consequence of the difference in selectivity of different materials in the CMP process. Despite this phenomenon, the height variation on the analyzed NW (with a diameter of (a)

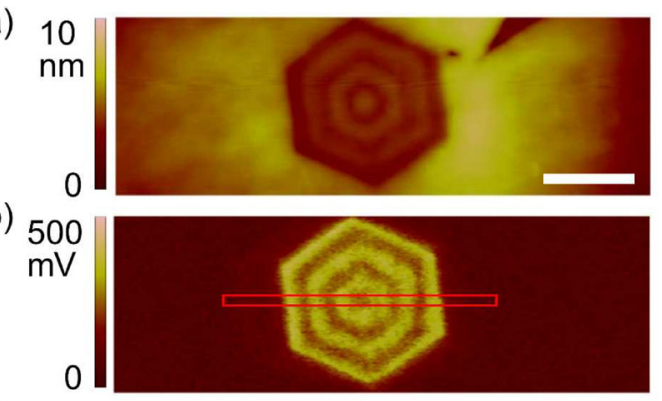

(c)

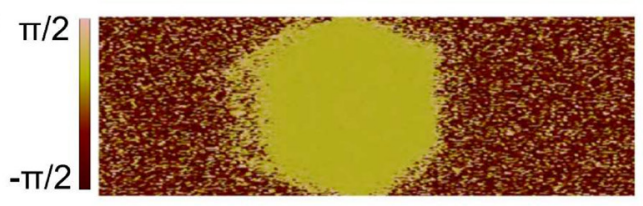

(d)

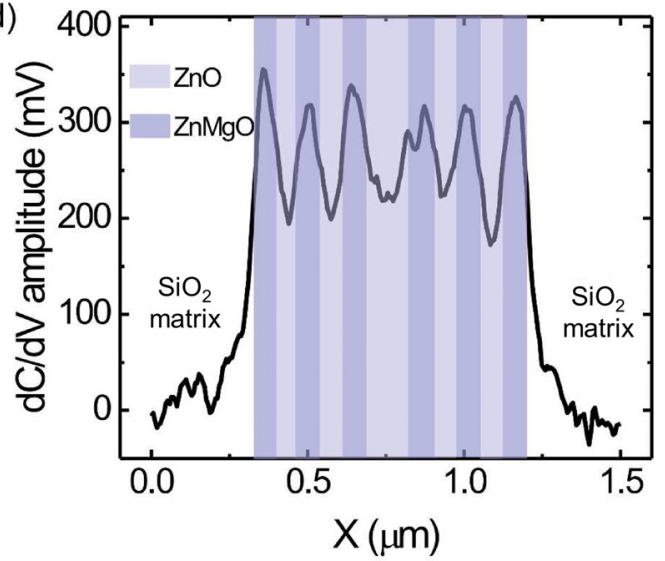

FIG. 2. Typical SCM result on a $\mathrm{ZnO} / \mathrm{ZnMgO}$ core-multishell NW. (a) Topography AFM image. (b) SCM data amplitude image showing clear contrast between $\mathrm{ZnO}$ and $\mathrm{ZnMgO}$ regions within the NW. (c) SCM data phase image exhibiting no difference between $\mathrm{ZnO}$ and $\mathrm{ZnMgO}$, indicating their identical conduction type. (d) Averaged $\mathrm{dC} / \mathrm{dV}$ amplitude profile of the red rectangle indicated in (b), showing $\mathrm{ZnO}$ giving rise to smaller SCM data amplitude due to its relatively high carrier concentration in comparison to ZnMgO. $V_{\mathrm{dc}}=-1 \mathrm{~V}$ and $V_{\mathrm{ac}}=1 \mathrm{~V}$ of $50 \mathrm{kHz}$ were used for the measurement scan. The scale bar in (a) is $0.5 \mu \mathrm{m}$. The scanned area is $3 \mu \mathrm{m} \times 1 \mu \mathrm{m}$.

$\sim 860 \mathrm{~nm}$ ) is less than $1 \mathrm{~nm}$. The SCM data image was recorded at $V_{\mathrm{dc}}=-1 \mathrm{~V}$ and $V_{\mathrm{ac}}=1 \mathrm{~V}$ for optimal contrast and is shown in Fig. 2(b). Apparently, the expected hexagonal shape for each NW is clearly observed. Furthermore, the $\mathrm{ZnO} / \mathrm{ZnMgO}$ core-multishell structure within the $\mathrm{NWs}$ is well detected as a result of the difference in the material composition. An averaged $\mathrm{dC} / \mathrm{dV}$ amplitude profile of the indicated rectangle is shown in Fig. 2(d). It is noticed that the $\mathrm{ZnMgO}$ layers give rise to $\mathrm{dC} / \mathrm{dV}$ peaks, whereas $\mathrm{dC} / \mathrm{dV}$ for the two $\mathrm{ZnO}$ shell layers dips, indicating relatively low and high local carrier densities for the $\mathrm{ZnMgO}$ and $\mathrm{ZnO}$ layers, respectively. This is consistent with previous works reporting that the increase in the $\mathrm{Mg}$ content in the $\mathrm{Zn}_{1-\mathrm{x}} \mathrm{Mg}_{\mathrm{x}} \mathrm{O}$ alloy can cause a decrease in the net electron concentration of the film. ${ }^{23}$ Additionally, the $\mathrm{SiO}_{2}$ matrix produces negligible SCM data amplitude due to the absence of free carriers. SCM characterization is known to be sensitive to the topographical variation. The large height change in the sample surface tends to result in varying contact areas of the tip with the sample, thus affecting the measured capacitance variation in an unwanted fashion. ${ }^{24}$ For our sample, after the polishing process, the roughness of the measured 
area is very small with the height variation less than $1 \mathrm{~nm}$, which is well acceptable for reliable SCM characterization. Besides, we noted that the SCM signal contrast between different regions can be reversed by tuning $V_{\mathrm{dc}}$, which further helped us conclude that the obtained SCM is genuinely related to the local electrical properties of the sample rather than the height variation effect. It should be mentioned that the investigated NW exhibits a larger shell layer thickness than expected. This is likely a result of the non-uniformity during the growth of NWs and their shells, which, in turn, indicates the potential of SCM to investigate the structural quality of grown shell layers on $\mathrm{NWs}$. The $\mathrm{dC} / \mathrm{dV}$ phase image [Fig. 2(c)] shows no large difference between $\mathrm{ZnO}$ and $\mathrm{ZnMgO}$, indicating the entire NW being of $n$-type conductivity, as expected for unintentionally doped $\mathrm{ZnO}$ and $\mathrm{ZnMgO}$.

We next show the SSRM investigation on the sample. In SSRM, by applying a direct voltage $\left(V_{\mathrm{dc}}\right)$ on the tip/sample system, the electrical resistance is measured which consists of different components including the local spreading resistance of interest $R_{\mathrm{s}}$, the barrier resistance between the tip and the sample $R_{\text {barrier }}$, the bulk resistance of the sample $R_{\text {bulk }}$, and the resistance of the tip $R_{\text {tip. }}$. In the ideal case, the total resistance is dominated by the local spreading resistance of the sample underneath the tip, thus enabling SSRM for 2D resistivity/carrier profiling. ${ }^{25}$ In practice, a stable electrical contact between the tip and the sample is critical to achieving reliable resistance recording, which is usually implemented by applying a relatively large contact-force of the AFM tip on the sample. ${ }^{26}$ In the case of silicon, a force larger than $15 \mu \mathrm{N}$ is needed for the probe to penetrate the native oxide layer on top of the silicon surface. ${ }^{25}$ Nevertheless, we found that a much lower force is enough for $\mathrm{ZnO}$ to obtain stable results of SSRM owing to its relative softness (Mohs hardness: 4.5 for $\mathrm{ZnO}$ versus 7 for silicon) and the absence of the insulating top layer. Figure 3 shows a group of $I-V$ characteristics under various tip forces on a $\mathrm{ZnO}$ substrate with a carrier concentration of $\sim 5 \times 10^{16} \mathrm{~cm}^{-3}$. Note that the

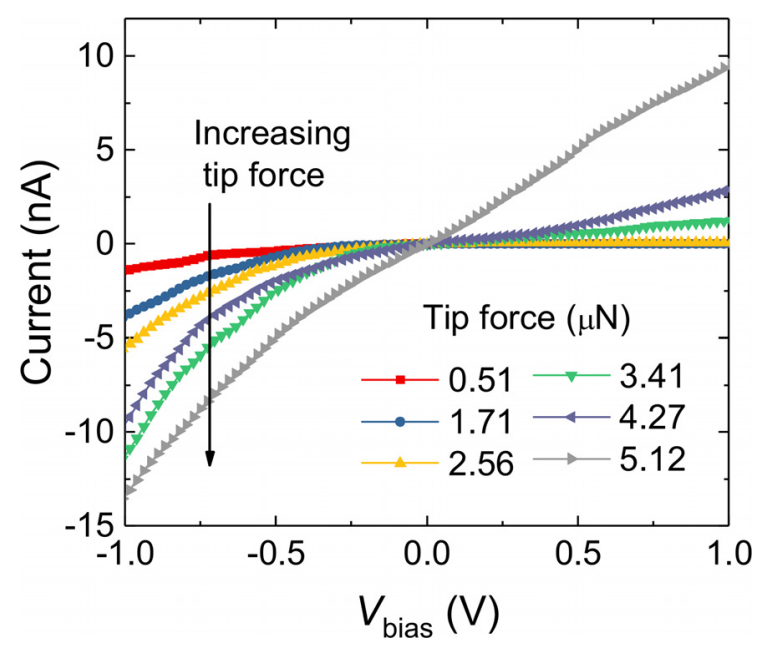

FIG. 3. Current-voltage characteristics of a tip/ZnO system by applying various tip forces on the bulk $\mathrm{ZnO}$ with a carrier concentration (n-type) of $\sim 5 \times 10^{16} \mathrm{~cm}^{-3}$. With the increasing tip force, there is an evolution from the Schottky behavior to near-ohmic behavior for the tip/ZnO contact. Voltage is applied to $\mathrm{ZnO}$. voltage was applied on the sample while the tip was grounded. As is observed, the tip-ZnO exhibits Schottky contact characteristics for relatively low tip forces. As the tip force increases, the current increases as well. After reaching a threshold point, the tip- $\mathrm{ZnO}$ contact becomes near-Ohmic, which can be attributed to possible $\mathrm{ZnO}$ phase transformation and created defect states. ${ }^{27}$ However, for our measurement on the NWs, we noticed that a force higher than $4 \mu \mathrm{N}$ already scratches violently the sample surface, hindering the acquisition of an image with acceptable spatial resolution and noise level. Therefore, a trade-off between the tip force and tip- $\mathrm{ZnO}$ characteristics was sought, and ultimately, we used a tip force of $1.5 \mu \mathrm{N}$ for measurements on the NWs.

For SSRM characterization on the NWs, it is worth pointing out that a flat surface is important for a reliable SSRM scan because severe height variations can result in significant shearing force of the tip on the sample, consequently rendering the measured resistance determined not by the sample region underneath the tip. For this reason, in our SSRM measurement, the investigated NW was selected with negligible surface roughness similar to that in SCM. We remind that the NW is not the same as in the SCM measurement because it was difficult to locate the identical NW in SCM after changing the tip for SSRM characterization. The typical SSRM result is reported in Fig. 4. Unsurprisingly, the NWs are unambiguously detected in SSRM resistance scans, revealing the distinction between the local electrical properties of different layers. Furthermore, through a comparison of the SSRM image with previous SCM images, a difference in spatial resolution is noticed with SSRM delivering a superior resolution. This occurs, despite the larger tip radius (typically $\sim 100 \mathrm{~nm}$ ) in SSRM than in SCM (typically 20-30 nm), because the spatial resolution in SSRM imaging is primarily

(a)

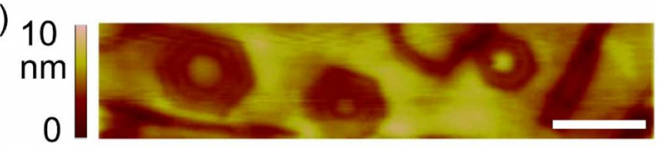

(b) 10

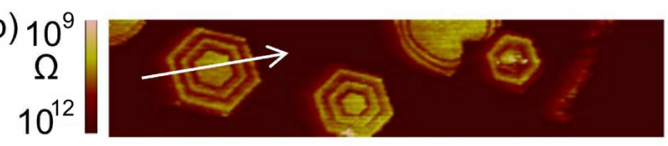

(c)

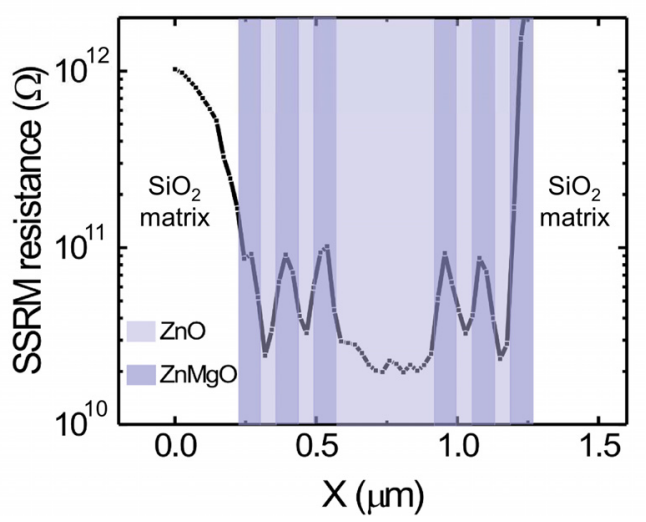

FIG. 4. SSRM result on the $\mathrm{ZnO} / \mathrm{ZnMgO}$ core-multishell $\mathrm{NW}$ sample. (a) Topography image. (b) Corresponding SSRM resistance image. (c) SSRM resistance profile along the white arrowed line in (b), revealing relatively low resistance corresponding to $\mathrm{ZnO}$ regions and high resistance for $\mathrm{ZnMgO}$. The scale bar is $1 \mu \mathrm{m}$. The scanned area is $6 \mu \mathrm{m} \times 1.3 \mu \mathrm{m}$. $V_{\text {bias }}$ $=-2 \mathrm{~V}$ and a tip force of $\sim 1.5 \mu \mathrm{N}$ were used. 
determined by the effective radius of the tip-sample contact, which can be significantly smaller than that of the tip, whereas the spatial resolution of SCM depends determinedly on the entire volume of the depletion region in response to the modulating voltage, which can far exceed the dimension of the tip. ${ }^{24,26}$ A profile of SSRM resistance along the line across a NW in Fig. 4(b) is plotted in Fig. 4(c). It is seen that the $\mathrm{ZnO}$ core and the $\mathrm{ZnO}$ shell layers $(<40 \mathrm{~nm})$ are detected with relatively low measured resistances during the scan in contrast to the $\mathrm{ZnMgO}$ layers. Here, considering the quasi$1 \mathrm{D}$ geometry structure of the characterized NW, the body of the NW is likely to contribute a larger portion of the total resistance and deserves a detailed discussion. For this purpose, the resistance of a uniformly doped NW can be expressed by $R_{\mathrm{NW}}=\rho h / s=4 h / \pi n q \mu d^{2}$. Then, assuming a NW with a height of $h=10 \mu \mathrm{m}$, a doping level of $n=10^{16} \mathrm{~cm}^{-3}$, a carrier mobility of $\mu=50 \mathrm{~cm}^{2} / \mathrm{V} \mathrm{s}$, and a diameter of $d=300 \mathrm{~nm}$, its resistance is evaluated to be $\sim 7 \times 10^{7} \Omega$. This value should represent an upper limit of the resistance of the characterized NW and is more than two orders of magnitude smaller than the measured total SSRM resistance. Therefore, despite the quasi-1D dimension, the body resistance of the NW is still negligible in this work. Regarding the measured resistances, which is almost one order higher for $\mathrm{ZnMgO}$ than for $\mathrm{ZnO}$, on the one hand, this is consistent with the analyzed result from SCM and can partly be ascribed to the higher carrier concentration in $\mathrm{ZnO}$. On the other hand, it was shown that the incorporation of $\mathrm{Mg}$ in $\mathrm{ZnO}$ can result in a pronounced reduction of the electron mobility for the film, likely due to Mg-related impurity scattering. ${ }^{28}$ Therefore, the relatively high resistance corresponding to $\mathrm{ZnMgO}$ layers in contrast to $\mathrm{ZnO}$ can be attributed to both its low carrier density and its reduced carrier mobility. Ideally, the carrier concentration and the local resistivity (determined by carrier density and carrier mobility) of a sample can be obtained from SCM and SSRM characterization, respectively, thereby enabling the access to carrier mobility by the combination of the two techniques. For example, this strategy has been used to investigate carrier motilities in SiGe quantum wells and that of the $\mathrm{Al}$ implanted layer in $4 \mathrm{H}-\mathrm{SiC} .^{29,30}$ However, to achieve reliable quantitative results, it is required that the measured signal ( $\mathrm{dC} / \mathrm{dV}$ amplitude in SCM and resistance in SSRM) be essentially determined by the very local property of the sample. We noticed that in Ref. 29, the quantum wells have a high doping concentration above $10^{18} \mathrm{~cm}^{-3}$, and the sample was scanned on the angle beveled surface with a magnification factor of 200. Similarly, in Ref. 30, the region of interest has a width of $>700 \mathrm{~nm}$ and the measurement was performed on the angle beveled surface of the sample. Under these circumstances, it is reasonable to derive the resistivity of the sample through the calibration curve approach. However, the case is different in this work, considering the thinness of the grown layers and the absence of a beveled surface. For instance, the resistance measured in SSRM at a particular position on the sample is not exclusively determined by the carrier density at this position but by the entire surrounding carrier profile. ${ }^{31}$ Therefore, it was relatively difficult to perform quantitative analysis on the carrier mobility. We believe that reliable analysis on this issue will require more studies on the properties of tip/ $\mathrm{ZnO}$ and tip/ $\mathrm{ZnMgO}$ contacts, as well as a deconvolution process by considering the lateral difference in the carrier concentration.

In summary, we have performed electrical scanning probe microscopy as SCM and SSRM to resolve 3-period $\mathrm{ZnO} / \mathrm{ZnMgO}$ heterostructures embedded in a core/shell configuration. Owing to the electrical properties of $\mathrm{ZnO}$ and $\mathrm{ZnMgO}$ differing from each other, distinct contrast can be obtained in both SCM and SSRM measurements, revealing sensitively a higher carrier density and a lower resistance relating to $\mathrm{ZnO}$ compared with neighboring $\mathrm{ZnMgO}$, respectively. By demonstrating 2D electrical imaging of core/shell nano-heterostructures with nanometer scale resolution using SCM and SSRM, this work opens up possibilities for accessing electronic characteristics of NW-based semiconducting materials, which is likely to benefit the optimization of fabrication processes towards their ultimate applications.

This work was supported by the French program ANR under the Madfiz Project No. ANR-11-NANO-013. Lin Wang would like to acknowledge the financial support from China Scholarship Council.

${ }^{1}$ W. I. Park, G. C. Yi, M. Y. Kim, and S. J. Pennycook, Adv. Mater. 15, 526 (2003).

${ }^{2}$ E.-S. Jang, J. Y. Bae, J. Yoo, W. I. Park, D.-W. Kim, G.-C. Yi, T. Yatsui, and M. Ohtsu, Appl. Phys. Lett. 88, 023102 (2006).

${ }^{3}$ L. J. Lauhon, M. S. Gudiksen, D. Wang, and C. M. Lieber, Nature 420, 57 (2002).

${ }^{4}$ C. Durand, C. Bougerol, J.-F. Carlin, G. Rossbach, F. Godel, J. Eymery, P.-H. Jouneau, A. Mukhtarova, R. Butté, and N. Grandjean, ACS Photonics 1, 38 (2014).

${ }^{5}$ X. Dai, A. Messanvi, H. Zhang, C. Durand, J. Eymery, C. Bougerol, F. H. Julien, and M. Tchernycheva, Nano Lett. 15, 6958 (2015).

${ }^{6}$ P.-C. Chang, Z. Fan, C.-J. Chien, D. Stichtenoth, C. Ronning, and J. G. Lu, Appl. Phys. Lett. 89, 133113 (2006).

${ }^{7}$ O. Hultin, G. Otnes, M. T. Borgstrom, M. Bjork, L. Samuelson, and K. Storm, Nano Lett. 16, 205 (2016).

${ }^{8}$ W. Vandervorst, C. Fleischmann, J. Bogdanowicz, A. Franquet, U. Celano, K. Paredis, and A. Budrevich, Mater. Sci. Semicond. Process. 62, 31 (2017).

${ }^{9}$ M. Holler, M. Guizar-Sicairos, E. H. Tsai, R. Dinapoli, E. Muller, O. Bunk, J. Raabe, and G. Aeppli, Nature 543, 402 (2017).

${ }^{10}$ G. Gramse, A. Kolker, T. Lim, T. J. Z. Stock, H. Solanki, S. R. Schofield, E. Brinciotti, G. Aeppli, F. Kienberger, and N. J. Curson, Sci. Adv. 3, e1602586 (2017).

${ }^{11}$ N. Amirifar, R. Lardé, E. Talbot, P. Pareige, L. Rigutti, L. Mancini, J. Houard, C. Castro, V. Sallet, E. Zehani, S. Hassani, C. Sartel, A. Ziani, and X. Portier, J. Appl. Phys. 118, 215703 (2015).

${ }^{12}$ C. C. Williams, Annu. Rev. Mater. Sci. 29, 471 (1999).

${ }^{13}$ P. Eyben, M. Xu, N. Duhayon, T. Clarysse, S. Callewaert, and W. Vandervorst, J. Vac. Sci. Technol., B 20, 471 (2002).

${ }^{14}$ A. Schulze, R. Cao, P. Eyben, T. Hantschel, and W. Vandervorst, Ultramicroscopy 161, 59 (2016).

${ }^{15}$ L. Wang, J. M. Chauveau, R. Brenier, V. Sallet, F. Jomard, C. Sartel, and G. Brémond, Appl. Phys. Lett. 108, 132103 (2016).

${ }^{16}$ L. Wang, V. Sallet, C. Sartel, and G. Brémond, Appl. Phys. Lett. 109, 092101 (2016).

${ }^{17}$ L. Wang, J. Laurent, J. M. Chauveau, V. Sallet, F. Jomard, and G. Brémond, Appl. Phys. Lett. 107, 192101 (2015).

${ }^{18}$ E. Przezdziecka, J. M. Sajkowski, M. Stachowicz, and A. Kozanecki, Thin Solid Films 643, 31 (2017).

${ }^{19}$ S. Choi, D. J. Rogers, E. V. Sandana, P. Bove, F. H. Teherani, C. Nenstiel, A. Hoffmann, R. McClintock, M. Razeghi, D. Look, A. Gentle, M. R. Phillips, and C. Ton-That, Sci. Rep. 7, 7457 (2017).

${ }^{20}$ N. Le Biavan, M. Hugues, M. Montes Bajo, J. Tamayo-Arriola, A. Jollivet, D. Lefebvre, Y. Cordier, B. Vinter, F. H. Julien, A. Hierro, and J. M. Chauveau, Appl. Phys. Lett. 111, 231903 (2017). 
${ }^{21}$ G. Perillat-Merceroz, P. H. Jouneau, G. Feuillet, R. Thierry, M. Rosina, and P. Ferret, J. Phys.: Conf. Ser. 209, 012034 (2010).

${ }^{22}$ L. Wang, B. Gautier, A. Sabac, and G. Bremond, Ultramicroscopy 174, 46 (2017).

${ }^{23}$ A. Hierro, G. Tabares, J. M. Ulloa, E. Muñoz, A. Nakamura, T. Hayashi, and J. Temmyo, Appl. Phys. Lett. 94, 232101 (2009).

${ }^{24}$ R. A. Oliver, Rep. Prog. Phys. 71, 076501 (2008).

${ }^{25}$ P. Eyben, J. Mody, S. C. Vemula, and W. Vandervorst, J. Vac. Sci. Technol., B 26, 338 (2008).

${ }^{26}$ A. Schulze, A. S. Verhulst, A. Nazir, T. Hantschel, P. Eyben, and W. Vandervorst, J. Appl. Phys. 113, 114310 (2013).
${ }^{27}$ F.-G. Kuang, X.-Y. Kuang, S.-Y. Kang, M.-M. Zhong, and A.-J. Mao, Mater. Sci. Semicond. Process. 23, 63 (2014).

${ }^{28}$ J. Tamayo-Arriola, M. Montes Bajo, N. Le Biavan, D. Lefebvre, A. Kurtz, J. M. Ulloa, M. Hugues, J. M. Chauveau, and A. Hierro, J. Alloys Compd. 766, 436 (2018).

${ }^{29}$ F. Giannazzo, V. Raineri, S. Mirabella, G. Impellizzeri, and F. Priolo, Appl. Phys. Lett. 88, 043117 (2006).

${ }^{30}$ F. Giannazzo, F. Roccaforte, and V. Raineri, Appl. Phys. Lett. 91, 202104 (2007).

${ }^{31}$ P. De Wolf, T. Clarysse, and W. Vandervorst, J. Vac. Sci. Technol., B 16, 320 (1998). 